\title{
Variations of the cephalic vein anterior to the clavicle in humans
}

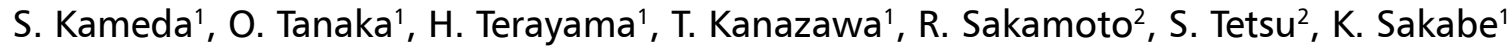 \\ ${ }^{1}$ Department of Anatomy, Division of Basic Medicine, Tokai University School of Medicine, Isehara-shi, Kanagawa, Japan \\ ${ }^{2}$ Department of Anaesthesiology, Tokai University School of Medicine, Isehara-shi, Kanagawa, Japan
}

[Received: 21 December 2017; Accepted: 30 January 2018]

\begin{abstract}
Background: Clinicians should understand that jugulocephalic vein (JCV) variants may be occasionally found. This study aims to classify JCV variants and obtain their frequency.

Materials and methods: We investigated anatomical variants of the cephalic vein in 55 human cadavers during a gross anatomy course at our medical school. Results: The percentage of JCVs that pass through the anterior part of the clavicle and anastomose to the jugular vein as per previous studies and our study was $2-5 \%$. Five cases with anastomosis between the cephalic and external jugular veins that pass through the anterior part of the clavicle were found. The courses were classified into $1 A, 1 B, 2 A$, and $2 B$. Type 1 extends beyond the clavicle and anastomoses with the external jugular vein. Type 2 follows the same course as type 1, but anastomoses with the subclavian vein. Subtype $A$ does not have a branch that anastomoses with the axillary vein, whereas subtype $B$ does. We encountered two cases of type $1 A$ and three of type $1 B$.

Conclusions: Four anatomical variants of the cephalic vein around the clavicle were identified. Clinicians' knowledge of these variants is expected to decrease possible complications if venous access via the cephalic vein is needed. (Folia Morphol 2018; 77, 4: 677-682)
\end{abstract}

Key words: cadavers, clavicle, jugulocephalic vein, anatomical variants

\section{INTRODUCTION}

The proximal part of the cephalic vein (CV) in the upper arm was not used frequently for instrumentation until recently. The upper part of the $\mathrm{CV}$ at the deltopectoral triangle has two distinct features; the vein location on the right under the skin and the proximal part of the vein that may be a tributary of the broad big axillary vein. These features allow clinicians to employ either the cut-down technique or the usual Seldinger technique $[15,23,24]$.

The CV has recently emerged as an alternative to the subclavian and external jugular veins for the implantation of catheters and artificial cardiac pacemakers $[16,21]$. In cases of central venous line in- sertion that requires critical central venous access from the subclavian vein, the CV cut-down method is employed at the deltopectoral triangle to insert a catheter under visual inspection [12]. Although vessel variation in the $\mathrm{CV}$ has not been reported to cause serious complications, it can cause some difficulties [2].

Contemporary anatomy textbooks, for example, Moore's Clinically Oriented Anatomy and Gray's Anatomy, describe the cephalic vein in the upper arm as traveling upward in the deltopectoral groove and joining the axillary vein just under the upper edge of the pectoralis minor muscle inferior to the clavicle in the axilla. The $\mathrm{CV}$, together with the cubital and basilic

Address for correspondence: Dr. O. Tanaka, Department of Anatomy, Division of Basic Medicine, Tokai University School of Medicine, Isehara-shi, Kanagawa, 259-1193 Japan, tel: +81463931121(Ext2503), e-mail: otanaka@is.icc.u-tokai.ac.jp 
veins, near the elbow fossa, is frequently employed as an adaptive venous injection site.

The aim of our work was to clarify vessel variations in the proximal portion of the CV and to classify the variations and frequency of occurrence. The vessels examined in this study provided sufficient information to accomplish this goal.

\section{MATERIALS AND METHODS}

We investigated the anatomy of the CV in 55 human cadavers during a gross anatomy course at our medical school (2013 and 2015). The cadavers were acquired from donors who have willed their body to medical education and science during life time. This study was approved by the institutional review board for clinical research (IRB number: 16R-140). Of the specimens examined, 35 were women and 20 were men. The cause of death did not affect the upper arm.

The region from the deltoid pectoral groove on both sides of the upper arm to the deltoid pectoral triangle at the clavicle under the platysma was examined. Anastomoses between CVs to the external jugular and axillary veins in the posterior triangle were investigated.

\section{RESULTS}

In 51 of the 55 cadavers studied, the CV followed a similar course bilaterally, ascending along the deltoid pectoral groove to the deltopectoral triangle and anastomosing with the axillary vein. In the first cadaver with an unusual course, the CV on both sides extended beyond the edge of the clavicle and anastomosed with the external jugular vein in the supraclavicular region (Figs. 1, 2).

The left CV appeared relatively thick and ascended at a shallow depth along the deltopectoral groove. The vein ran beyond the edge of the clavicle after receiving a small-sized tributary from the deltoid muscle in the subclavian fossa and drained into the external jugular vein in the supraclavicular region (Fig. 1). The course of the right CV appeared very similar to that of the left, but without the smaller tributary beyond the clavicle (Figs. 1, 2).

In the second of the four cadavers, the CV joined the external jugular vein beyond the edge of the clavicle on one side without joining the axillary vein (Figs. 3, 4).

In the third and fourth cadavers, the CV is divided into two branches anterior to the clavicle; one of the branches joined the axillary vein, while the

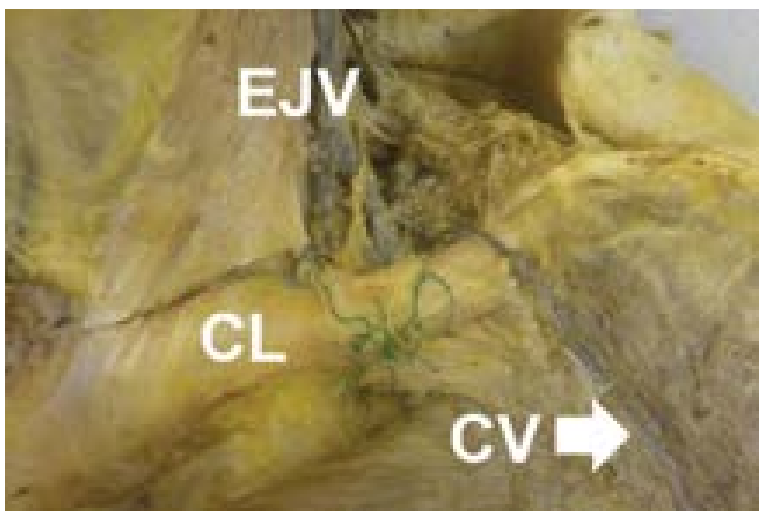

Figure 1. Left cephalic vein in the first cadaver. The left cephalic vein ascended along the deltopectoral groove and joined the left jugular vein beyond the clavicle; $\mathrm{CL}$ — clavicle; $\mathrm{CV}$ — cephalic vein; EJV — external jugular vein.

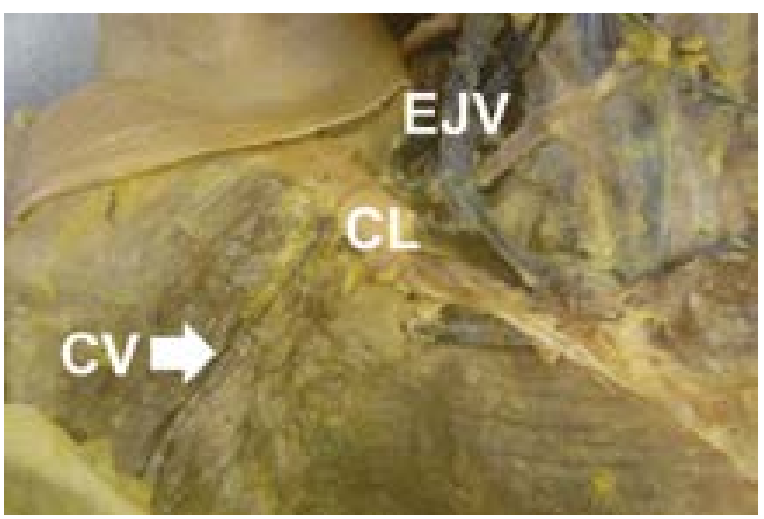

Figure 2. Right cephalic vein in the first cadaver. The right cephalic vein ascended along the deltopectoral groove and joined the right jugular vein beyond the clavicle; $\mathrm{CL}$ - clavicle; $\mathrm{CV}$ — cephalic vein; EJV — external jugular vein.

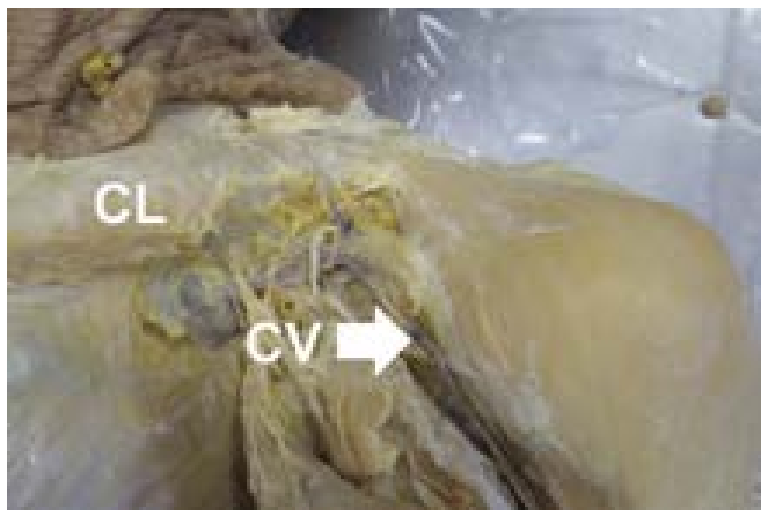

Figure 3. Left cephalic vein in the second cadaver. The left cephalic vein in the second cadaver divided into two branches in the deltopectoral fossa; $\mathrm{CL}$ - clavicle, $\mathrm{CV}$ — cephalic vein.

other joined the external jugular vein beyond the clavicle (Figs. 5,6). The relatively thicker left CV in 


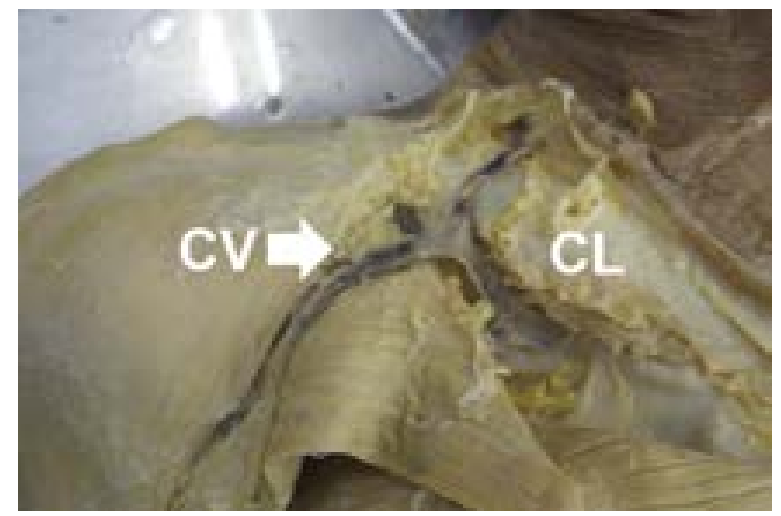

Figure 4. Right cephalic vein in the second cadaver. The right cephalic vein in the second cadaver divided into two branches in the deltopectoral fossa; $\mathrm{CL}$ - clavicle; $\mathrm{CV}$ — cephalic vein.

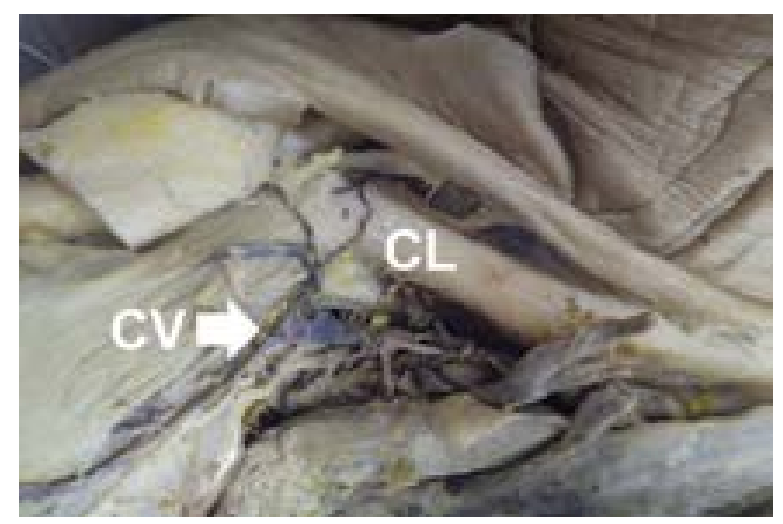

Figure 5. Right cephalic vein in the third cadaver. The right cephalic vein in the third cadaver divided into two branches in the deltopectoral fossa. One of the branches joined the axillary vein, while the other joined the external jugular vein beyond the clavicle; $\mathrm{CL}$ - clavicle; CV — cephalic vein.

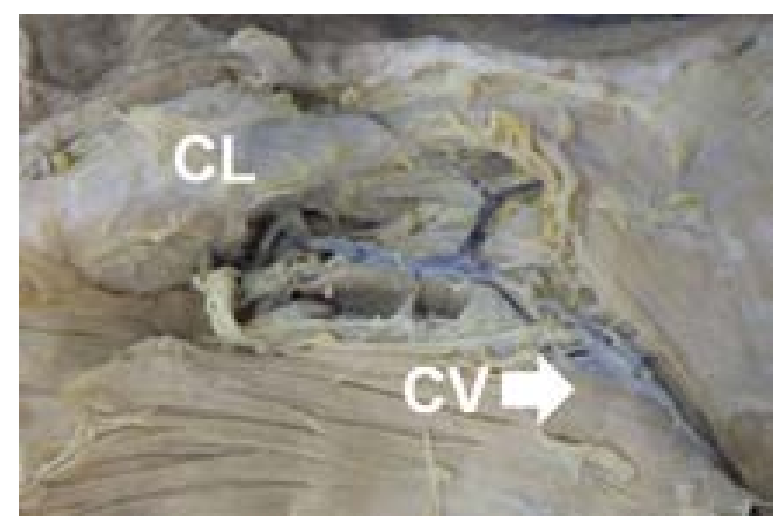

Figure 6. Left cephalic vein in the fourth cadaver. The left cephalic vein in the fourth cadaver divided into two branches in the deltopectoral fossa. The thinner branch joined the external jugular vein beyond the clavicle, and the other, a relatively thicker branch, joined the axillary vein; $\mathrm{CL}$ - clavicle; $\mathrm{CV}$ — cephalic vein. the third cadaver ascended along the deltopectoral groove and bifurcated in the subclavian fossa (Fig. 5). A thin branch ran beyond the edge of the clavicle and opened into the external jugular vein. A thick branch anastomosed with the axillary vein beyond the upper edge of the pectoralis minor muscle under the clavicle. In addition, the right CV ascended along the deltopectoral groove and divided into two branches in the subclavian fossa. A relatively thinner branch opened into the external jugular vein beyond the edge of the clavicle, and a thicker branch entered the axillary vein under the clavicle.

In the fourth cadaver, the right CV divided into two branches at the clavicle (Fig. 6). The thinner branch flowed into the external jugular vein in the supraclavicular region and the other, a relatively thicker branch, flowed into the axillary vein.

The CVs shown in Figures 3-6 divided into two branches before passing anterior to the clavicle. One branch joined the external jugular vein in the supraclavicular region and the other branch joined the axillary vein.

In the 55 studied cadavers, 3 of $110 \mathrm{CVs}$ joined the jugular vein beyond the edge of the clavicle (Figs. 1, 2). Furthermore, three other CVs divided into two branches at the deltopectoral triangle. One branch joined the axillary vein and the other joined the external jugular vein beyond the clavicle (Figs. 3-6). A distinctive course was observed on both sides in two of the four cadavers, in which the cephalic vein extended beyond the clavicle. Based on previous reports and the results obtained from this study, we classified the variations in the proximal region of the $\mathrm{CV}$ around the clavicle into four patterns (Fig. 7) [1, 3-10, 13, 14, 17-20, 22, 25].

The papers we reviewed were in English or Japanese languages. A section of one of the papers was in French [7]. This paper stated that variants of the external jugular vein passed over the clavicle and anastomosed with the CV. Furthermore, we did not consider small tributaries, and single case reports were excluded. The course of the CV was classified into two types $(1,2)$ and two subtypes $(A, B)$. Type 1 follows a course beyond the clavicle and anastomoses with the external jugular vein. Type 2 follows the same course beyond the clavicle, but unlike type 1 , it anastomoses with the subclavian vein. Subtype $A$ does not anastomose with the axillary vein, whereas subtype $B$ does. In 5 of the 55 cadavers, the CV was located posterior to the clavicle. Two of the specimens had type $1 \mathrm{~A}$ cephalic veins and 3 had type $1 \mathrm{~B}$. 


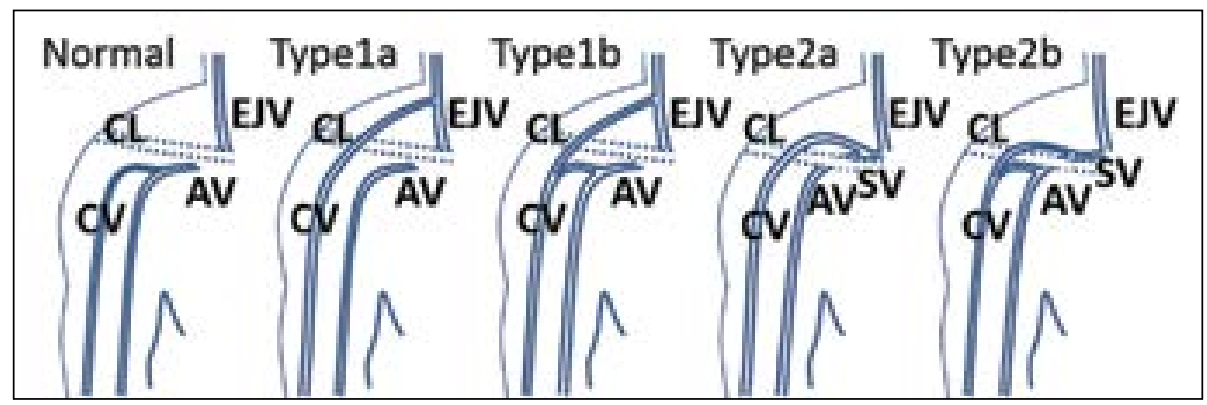

Figure 7. Variations in the course of the cephalic vein (CV) around the clavicle (CL) were classified into four patterns. Type $1 \mathrm{~A}-$ the cephalic vein did not join the axillary vein in the deltopectoral triangle, but anastomosed with the external jugular vein beyond the clavicle. Type $1 \mathrm{~B}-$ the cephalic vein joined the axillary vein in the deltopectoral triangle and the external jugular vein beyond the clavicle. Type $2 \mathrm{~A}-$ the cephalic vein did not join the axillary vein in the deltopectoral triangle, but joined the subclavian vein beyond the clavicle. Type $2 B-$ the cephalic vein joined the axillary vein and the subclavian vein beyond the clavicle; AV — axillary vein; EJV — external jugular vein; SV — subclavian vein.

Table 1. Variations of the cephalic vein with a supraclavicular course

\begin{tabular}{|c|c|c|c|c|c|}
\hline Articles & Type 1A & Type 1B & Type 2A & Type 2B & Total \\
\hline Present cases & $2 / 110(1.8 \%)$ & $4 / 110(3.6 \%)$ & & & $6 / 110(5.4 \%)$ \\
\hline Mochizuki [9] & 4/120 (3.3\%) & & & & 4/120 (3.3\%) \\
\hline Hieda [4] & & & $2 / 100(2.0 \%)$ & & $2 / 100(2.0 \%)$ \\
\hline Tokano et al. [19] & & & $7 / 221(3.1 \%)$ & & $7 / 221(3.1 \%)$ \\
\hline Loukas et al. [8] & & & $4 / 200(2.0 \%)$ & & $4 / 200(2.0 \%)$ \\
\hline Świętoń et al. [18] & & & & 6/1828 (0.3\%) & $6 / 1828(0.3 \%)$ \\
\hline Świętoń et al. [17] & $2 / 324(0.6 \%)$ & 12/324 (3.7\%) & & & 14/324 (4.3\%) \\
\hline Deslaugiers et al. [3] & $2 / 100(2.0 \%)$ & $11 / 100(11 \%)$ & & & $13 / 100(13 \%)$ \\
\hline Plakornkul and Manoonpol [14] & $5 / 208(2.4 \%)$ & $10 / 208(4.8 \%)$ & & & $15 / 208(7.2 \%)$ \\
\hline Le Saout et al. [7] & & $5 / 263(1.9 \%)$ & & & $5 / 263(1.9 \%)$ \\
\hline Anastasopoulos et al. [1] & & 2 & & & 2 \\
\hline De Maria and Cappelli [2] & & & 1 & & 1 \\
\hline Lau et al. [6] & & & 1 & & 1 \\
\hline Nayak and Soumya [10] & & 1 & & & 1 \\
\hline Kim and Han [5] & 1 & & & & 1 \\
\hline Patil et al. [13] & & & 1 & & 1 \\
\hline Villegas et al. [22] & 1 & & & & 1 \\
\hline Wysiadecki et al. [25] & & 1 & & & 1 \\
\hline Trigano et al. [20] & & & 1 & & 1 \\
\hline Total & 17 & 46 & 17 & 6 & 86 \\
\hline
\end{tabular}

Values represent frequencies and percentages. All the percentages were rounded to the nearest whole number $[1,2,3,4,5,6,7,8,9,10,13,14,17,18,19,20,22,25]$.

We classified the veins in the cadavers described in previous papers and reports according to the above patterns (Table 1). The gender, race, and side of the body studied were not recorded in some of these reports. For 86 cadavers described previously, the $\mathrm{CV}$ ran beyond the clavicle. These veins included 17 type $1 A$, 46 type $1 B, 17$ type $2 A$, and 6 type $2 B$. The percentage of each $\mathrm{CV}$ type and subtype in all the reported cases is listed in Table 1. Type 1A comprised approximately $0.4 \%$, type $1 \mathrm{~B} 1.2 \%$, type $2 \mathrm{~A} 0.4 \%$, and type $2 \mathrm{~B} 0.2 \%$. The proportion of type $1 \mathrm{~B}$ was the highest among the four patterns.

\section{DISCUSSION}

Our specimens were Japanese self-donated cadavers ( 35 men and 20 women). None of the bodies died from external factors or accident. The limitations of our study include the proportional difference in 
appearance of jugulocephalic vein (JCV) in between the cadavers and the other reports could be explained later in this discussion.

The papers listed in Table 1 reported the course of the CV anterior to the clavicle, but those papers did not find variations in these cases. We found four variations of the $\mathrm{CV}$ anterior to the clavicle based on the following conditions: whether the $\mathrm{CV}$ is anastomosed to the axillary vein in the deltopectoral triangle or not and whether the $\mathrm{CV}$ is anastomosed to the subclavian vein or external jugular vein beyond the clavicle. In type 1B, the CV joined the axillary vein in the deltopectoral triangle and also joined the external jugular vein beyond the clavicle. This type has the highest proportion among the four patterns.

To briefly summarise our results, five cadavers were found in which the CV anastomosed with the external jugular vein beyond the clavicle. Eighty-five other cases in which the $\mathrm{CV}$ ran beyond the clavicle were reported in previous studies. The variations in the courses of these $C V s$ were classified into four types: $1 A, 1 B, 2 A$, and $2 B$ as detailed above. In type $1 A$, the cephalic vein did not join the axillary vein in the deltopectoral triangle but anastomosed with the external jugular vein beyond the clavicle. In type 1B, the $\mathrm{CV}$ joined the axillary vein in the deltopectoral triangle and also joined the external jugular vein beyond the clavicle. In type $2 \mathrm{~A}$, the CV did not join the axillary vein in the deltopectoral triangle, but joined the subclavian vein beyond the clavicle. In type $2 \mathrm{~B}$, the $\mathrm{CV}$ joined the axillary and subclavian veins beyond the clavicle. Our five cases were classified as types $1 \mathrm{~A}$ and $1 \mathrm{~B}$.

From the viewpoint of the development of the vein in relation to the clavicle, we wondered why type 1B was relatively common in the proximal part of the CV. Type 1B has two vessel courses that anastomose with the external jugular and axillary veins. According to Padget [11], during development, the CV initially extends from the distal end to the proximal end of the arm, rather than from the proximal to the distal ends. The CV later becomes the jugular CV, also called the JCV, which anastomoses with the primitive subclavian vein very close to the internal jugular vein. Eventually, it develops into the external jugular and subclavian veins. Around the same time, the primitive clavicle appears under the JCV, while the anterior part of the JCV at the clavicle disappears. Thus, type $1 \mathrm{~A}$ is considered a remnant of the anterior part of the JCV, which normally disappears. Type 1B is considered the connection that leads back into the main stream when the anterior part of the JCV does not disappear. Type $2 \mathrm{~A}$ is considered the same as type $1 \mathrm{~A}$, with a connection to the subclavian vein that does not exist in type 1. Type $2 B$ is considered the same as type $1 B$, also with a connection to the subclavian vein that does not exist in type 1.

The unusual courses of the CV beyond the clavicle were found on both sides in some of the cadavers at our university, and one side of the JCV was thicker than the other. However, none of the other papers mentioned this detail, with the exception of Anastasopoulos et al. [1, 17]. Radiological studies of unusual JCVs focused on one side only, which may explain why the percentage of unusual courses reported on both sides was low.

The percentage of JCVs in all publications, other than case reports, was approximately $2 \%$. Excluding reports on catheterisation and angiography, the percentage of unusual JCVs in cadaveric reports was approximately $4 \%$. The reason for the difference is that the reports on catheterisation and angiography were based on observations of only one side. Our results indicate a high probability that unusual JCVs occur bilaterally. Some of the catheterisation and angiography studies may have overlooked the JCV because only one side was observed. The percentage of unusual JCV calculated based on the number of dissections could be higher than that reported in the catheterisation and angiography studies. Therefore, if both arms were considered, the occurrence in all cases should be closer to $4 \%$. Future studies can evaluate both arms with a larger pool of cadavers to confirm the incidence of unusual JCVs. Considering the generic vein development process, multiple veins converge into specific courses at a young age. This means that the courses of the veins continue to change until a specific age. If possible, we would like to clarify the age when this alteration occurs by identifying the percentage of unusual CVs in the upper arm according to age. Compared to the subclavian and external jugular veins, the proximal part of the $\mathrm{CV}$ is known to be associated with fewer complications when used for access to the central vein to administer medications. If necessary, either venous puncture or the cut-down approach with direct visualisation in the deltopectoral groove can be employed for the implantation of a catheter or a cardioverter-defibrillator. Thus, cardiologists or oncologists involved in catheter placement should be aware of the occasional occurrence of 
this unusual JCV variant, especially the type without anastomosis to the axillary vein.

\section{CONCLUSIONS}

Based on the result of 110 samples, from our study and previous reports, the proximal part of $2 \%$ to $4 \%$ of CVs around the clavicle followed a course beyond the clavicle. These cases were classified into four types according to the anastomosis, namely, types $1 \mathrm{~A}, 1 \mathrm{~B}$, $2 \mathrm{~A}$, and $2 \mathrm{~B}$. Knowledge of these anatomical variants could avoid serious complications during catheter implantation.

\section{Acknowledgements}

The authors wish to thank Noriyuki Kosemura for his excellent technical support.

\section{REFERENCES}

1. Anastasopoulos N, Paraskevas G, Apostolidis S, et al. Three superficial veins coursing over the clavicles: a case report. Surg Radiol Anat. 2015; 37(9): 1129-1131, doi: 10.1007/ s00276-015-1445-4, indexed in Pubmed: 25681974.

2. De Maria E, Cappelli S. Cephalic vein with a supraclavicular course: rare, but do not forget it exists! J Cardiovasc Med (Hagerstown). 2017; 18(9): 727-728, doi: 10.2459/ JCM.0b013e32836132d6, indexed in Pubmed: 23756408.

3. Deslaugiers B, Vaysse $P$, Combes JM, et al. Contribution to the study of the tributaries and the termination of the external jugular vein. Surg Radiol Anat. 1994; 16(2): 173-177, indexed in Pubmed: 7940081.

4. Hieda G. About japanese subcutaneous veins in upper limb. Acta Medica. 1927; 1: 54-59.

5. Kim DI, Han SH. Venous variations in neck region: cephalic vein. Int J Anat Var. 2010; 3: 208-210, doi: 10.7860/ JCDR/2014/9396.5113.

6. Lau EW, Liew R, Harris S. An unusual case of the cephalic vein with a supraclavicular course. Pacing Clin Electrophysiol. 2007; 30(5): 719-720, doi: 10.1111/j.15408159.2007.00736.x, indexed in Pubmed: 17461885.

7. Le Saout J, Vallee B, Person $\mathrm{H}$, et al. [Anatomical basis for the surgical use of the cephalic vein (V. Cephalica). 74 anatomical dissections. 189 surgical dissections]. J Chir (Paris). 1983; 120(2): 131-134, indexed in Pubmed: 6853618.

8. Loukas M, Myers CS, Wartmann ChT, et al. The clinical anatomy of the cephalic vein in the deltopectoral triangle. Folia Morphol. 2008; 67(1): 72-77, indexed in Pubmed: 18335417.

9. Mochizuki S. Japanese cervical veins. Keio J Med. 1925; 5: 245-314.

10. Nayak BS, Soumya KV. Abnormal formation and communication of external jugular vein. Int J Anat Var. 2008; 1: 15-16.
11. Padget $\mathrm{DH}$. The cranial venous system in man in reference to development, adult configuration, and relation to the arteries. Am J Anat. 1956; 98(3): 307-355, doi: 10.1002/ aja.1000980302, indexed in Pubmed: 13362118.

12. Parsonnet $V$, Roelke $M$. The cephalic vein cutdown versus subclavian puncture for pacemaker/ICD lead implantation. Pacing Clin Electrophysiol. 1999; 22(5): 695-697, indexed in Pubmed: 10353126.

13. Patil RA, Rajgopal L, lyer P. Absent external jugular vein: ontogeny and clinical implications. Int J Anat Var. 2013; 6: 103-105.

14. Plakornkul V, Manoonpol C. The patterns of the cephalic veins termination. Siriraj Med J. 2006; 58: 1204-1207.

15. Seldinger SI. Catheter replacement of the needle in percutaneous arteriography; a new technique. Acta Radiol. 1953; 39(5): 368-376, indexed in Pubmed: 13057644.

16. Shimada H, Hoshino K, Yuki M, et al. Percutaneous cephalic vein approach for permanent pacemaker implantation. Pacing Clin Electrophysiol. 1999; 22(10): 1499-1501, indexed in Pubmed: 10588152.

17. Świętoń EB, Steckiewicz R, Grabowski M, et al. Selected clinical challenges of a supraclavicular cephalic vein in cardiac implantable electronic device implantation. Folia Morphol. 2016; 75(3): 376-381, doi: 10.5603/FM.a2015.0125, indexed in Pubmed: 26711650.

18. Świętoń E, Steckiewicz R, Stolarz P, et al. Supraclavicular course of the cephalic vein - implications for cardiac electronic device implantation. Folia Cardiol. 2015; 10(5): 200-203.

19. Tokano T, Nakazato $Y$, Shiozawa T, et al. Variations in cephalic vein venography for device implantation-Relationship to success rate of lead implantation. J Arrhythm. 2013; 29(1): 9-12, doi: 10.1016/j.joa.2012.05.009.

20. Trigano A, D'Ivernois C, Levy S, et al. Preclavicular route following cephalic venous cutdown for pacemaker or defibrillator lead implantation. Pacing Clin Electrophysiol. 2007; 30(1): 147-149, doi: 10.1111/j.1540-8159.2007.00593.x, indexed in Pubmed: 17241333.

21. Tse HF, Lau CP, Leung SK. A cephalic vein cutdown and venography technique to facilitate pacemaker and defibrillator lead implantation. Pacing Clin Electrophysiol. 2001; 24(4 Pt 1): 469-473, indexed in Pubmed: 11341084.

22. Villegas F, Restrepo A, Rodríguez D, et al. Supraclavicular course of the cephalic vein. Int J Case Rep Imag. 2014; 5(4): 281, doi: 10.5348/ijcri-201458-cr-10369.

23. Webre DR, Arens JF. Use of cephalic and basilic veins for introduction of central venous catheters. Anesthesiology. 1973; 38(4): 389-392, indexed in Pubmed: 4707584.

24. Wendth AJ. Peripheral arteriography an overview of its origins and present status. CRC Crit Rev Clin Radiol Nucl Med. 1975; 6(3): 369-401, indexed in Pubmed: 1097188.

25. Wysiadecki G, Polguj M, Topol M. Persistent jugulocephalic vein: case report including commentaries on distribution of valves, blood flow direction and embryology. Folia Morphol. 2016; 75(2): 271-274, doi: 10.5603/FM.a2015.0084, indexed in Pubmed: 26383511. 